\title{
Nise: No Coração da Loucura Uma Análise do Contexto do Filme e a Evolução Legislativa Sobre Saúde Mental
}

\section{Amanda Oliveira da Câmara Moreira}

Mestre em Direito Constitucional (UFRN). Especialista em Direito Constitucional (UNI-RN). Professora (Ufersa e Unirb). Advogada. Presidente da Comissão de Direito da Moda (OAB RN). Bacharela em Direito pelo Centro Universitário do Rio Grande do Norte. advamandacamara@outlook.com

\section{Marcelo Maurício da Silva}

Doutor em Ciências Jurídicas e Sociais pela Universidad del Museo Social Argentino - Umsa. Especialista em Direito Internacional pela Universidade Federal do Rio Grande do Norte. Especialista em Direito e Processo do Trabalho pela Escola da Magistratura Trabalhista do TRT da 21a Região/Esmat 21. Professor de Graduação e de Pós-Graduação do curso de Direito do UNI-RN. Advogado militante na seara trabalhista. marcelomauricio@unirn.edu.br

\section{Fabiana Dantas Alves Soares da Mota}

Mestre em Direito Constitucional pela UFRN. Especialista em Direito Público. MBA em Planejamento e Gestão Estratégica. Professora do departamento de Direito Privado da UFRN. Advogada. Membro da Comissão de Direito da Moda OAB RN e Gesto (UFRN). fabianadsamota@gmail.com

Partindo-se do filme "Nise - no coração da loucura", como marco temporal inicial, com base no ano de 1944 até o ano de 2018, realiza-se um retalho no tempo analisando as legislações vigentes desde a época inicial até a atualidade, no que se refere à saúde mental, seja no tratamento médico ou no local de internação dos pacientes, com o objetivo de demonstrar a real evolução legislativa e casuística, seja ela internacional ou nacional. A metodologia aplicada foi o método indutivo e o histórico. O objetivo do presente texto é demonstrar, por meio de um recorte cinematográfico, as implicações jurídicas dadas no caso do tratamento dos pacientes que possuem problemas de saúde mental. Como considerações finais, o que se observa é uma evolução legislativa no que respeita à tutela dos deficientes mentais, com tratamentos mais humanizados, priorizando a dignidade da pessoa humana.

Palavras-chave: Saúde mental. Direitos humanos. Deficiente mental. Cinema.

\section{NISE: IN THE HEART OF MADNESS. A FILM CONTEXT ANALYSIS} AND THE LEGISLATIVE EVOLUTION ON MENTAL HEALTH

\section{ABSTRACT}

Starting from the film "Nise - in the heart of madness" as the initial time frame, based on the year 1944 until the year 2018, a retail in time is analyzed the laws in force from the initial time to the present time, in the which deals with mental health, either in the medical treatment or in the place of hospitalization of the patients, in order to demonstrate the actual legislative and casuistic evolution, be it international or national. The applied methodology was the inductive and historical method. The purpose of this paper is to demonstrate, through a cinematographic clipping, the legal implications given in the case of the treatment of patients with mental health problems. As final considerations what is observed is a legislative evolution regarding the protection of the mentally disabled, with more humanized treatments, prioritizing the dignity of the human person.

Keywords: Mental health. Human rights. Mentally retarded Movie theater.

1 Introdução. 2 Contexto do Filme no Engenho Doce e a Casa de Repouso de Guararapes: a Arte e o Direito - Dois Hospitais, uma Única Realidade. 3 Evolução Legislativa. 3.1 Capacidade: uma Análise da Pessoa com Deficiência. 3.2 Análise dos Tratamentos à Luz da Dignidade da Pessoa Humana. 4 Saúde Mental: Legislação e Novos Tratamentos. 5 Considerações Finais. 6 Referências. 


\section{Introdução}

O presente trabalho tem como base o filme "Nise - no coração da loucura" (2015), o qual retrata o contexto de um hospital psiquiátrico no subúrbio do Rio de Janeiro no ano de 1944. A pesquisa é realizada mediante a realidade mostrada, por meio de um viés comparativo acerca do tratamento dado aos pacientes à luz da legislação vigente à época e questões relacionadas a maus-tratos e tortura, até então não amparados pelos textos legais até o contexto hodierno. Logo, o objetivo deste artigo é demonstrar a importância e as consequências jurídicas e psicológicas no tratamento dos pacientes mentais.

Partindo desta premissa, foi dado um aporte inicial do que trata a película, com um breve histórico dos tratamentos utilizados (lobotomia e eletrochoque, por exemplo), todos válidos na época, cujo objetivo era realizar uma ponte entre a realidade retratada e a legislação pátria e internacional.

Em seguida, realizou-se uma evolução legislativa desde aquela vigente na época até o presente ano. Para isto, houve uma divisão capitular para o desenvolvimento disto, passando, inicialmente, a analisar questões referentes à capacidade dos pacientes com deficiência mental, desde o Código Civil de 1916 e dos documentos internacionais que tratam sobre pessoas com deficiência, direitos humanos e saúde mental, além da análise de caso concreto por violação de Direitos Humanos (caso Ximenes Lopes) até o atual Estatuto da Pessoa com Deficiência.

Em seguida foram abordadas questões relacionadas aos tratamentos utilizados nos pacientes à luz dos direitos humanos e da dignidade da pessoa humana, numa verdadeira evolução de tais direitos, por meio do que se vislumbra a permissão de maus-tratos e torturas, em época em que a Constituição Federal de 1937 era omissa, e não havia documentos internacionais que vedassem tais atos, até chegar ao contexto da Declaração Universal de Direitos Humanos de 1948 e a Constituição Cidadã de 1988.

Após a análise mais individual de tais premissas referentes aos pacientes, observou-se as evoluções legislativas lato sensu no que diz respeito à saúde mental, realizando-se um breve histórico de leis que tratavam sobre o tema.

A metodologia utilizada no presente artigo foi o método indutivo e o histórico, desenvolvida mediante um viés jurídico-psicológico, com base em pesquisa bibliográfica referente à saúde mental, capacidade, dignidade da pessoa humana, técnicas de intervenções cirúrgicas em pacientes portadores de deficiência mental e legislações em geral, com o escopo de demonstrar a relevância jurídica da evolução na tutela destas pessoas. Além disso, utilizou-se da análise de caso concreto para fomentar mais ainda a importância da humanização do tratamento dos pacientes mentais.

A ideia de unir o filme com o Direito demonstra o caráter interdisciplinar do presente artigo, tendo em vista que a questão da modificação dos tratamentos dos pacientes mentais liga-se com a evolução legislativa pátria e internacional acerca da saúde mental.

Esta premissa baseia-se em questões principalmente relacionadas à humanização dos tratamentos e à exclusão de procedimentos cirúrgicos, como a lobotomia, que rechaçava qualquer possibilidade de melhora no quadro dos pacientes, unindo-se, assim, as atividades médico-psiquiátricas e o Direito. 
Desse modo, a demonstração da evolução do tratamento psiquiátrico foi realizada com o enfoque construtivo e de mudança de paradigmas, tomando como parâmetro legislações internacionais, nacionais e do Estado do Rio Grande do Norte.

\section{Contexto do Filme no Engenho Doce e a Casa de Repouso de Guararapes: a arte e o direito - dois hospitais, uma única realidade}

A obra cinematográfica "Nise - no coração da loucura" trata da história verídica da doutora Nise da Silveira (Glória Pires), psiquiatra e precursora do tratamento de terapia ocupacional no Brasil. A história se passa no ano de 1944 e retrata a realidade do Hospital Psiquiátrico Engenho Doce no Rio de Janeiro/Brasil.A médica, recém-saída da prisão, passa a clinicar novamente no referido hospital. No retorno ao trabalho, no início da película, é proferida uma palestra pelos psiquiatras que laboravam no hospital, demonstrando nos pacientes as técnicas consideradas mais modernas para a época: lobotomia e eletrochoque.

A primeira explanação tratou da lobotomia ou leucotomia, que consiste em uma cirurgia no cérebro para a retirada dos lobos frontais ao talo. Desenvolvida a partir do ano de 1935, este procedimento era considerado moderno e utilizado em pacientes psiquiátricos, em sua maioria nos casos de esquizofrênicos mais graves.

Esta técnica tinha como consequência a perda ou a diminuição de reação dos pacientes, ou seja, a perda de emoções, tornando-os mais calmos, mas não curados. Logo, aqueles que passavam por este procedimento cirúrgico ficavam apáticos aos sentimentos externos.Em virtude da criação de novas técnicas menos invasivas e de medicamentos específicos para o tratamento dos pacientes, esta deixou de ser utilizada com o passar dos anos. Nesse sentido,

Utilizadas por cerca de vinte anos no Brasil, mais de mil pessoas, inclusive estrangeiros e crianças, foram submetidas às psicocirurgias. Com o advento dos psicofármacos na década de 1950, estes procedimentos desapareceram dos hospitais psiquiátricos tão rápido quanto foram esquecidos pela história recente da medicina brasileira. Com os avanços da neurologia, novas técnicas muito mais precisas voltaram a ser utilizadas na década de 1970. Atualmente, são raramente indicadas em vista do grande número de opções de tratamentos psiquiátricos disponíveis (MASIEIRO, 2003, p. 2).

No Brasil, o relato da utilização da técnica ocorreu predominantemente nos anos de 1942 a 1956, conforme aduz Masieiro (2003, p. 7), com estudos específicos sobre o tema, sendo esta a primeira técnica destacada no filme.

A segunda técnica utilizada era o eletrochoque, ou eletroconvulsoterapia, que consistia na utilização de choques elétricos no cérebro dos pacientes mentais, induzindo o paciente a entrar em convulsão.

No contexto do longa-metragem, a doutora Nise da Silveira pergunta ao médico, que demonstrou as técnicas no paciente, se existia uma voltagem correta para aplicar ao paciente e quais os benefícios trazidos pelo tratamento. $O$ médico apenas limitou-se a responder que a própria prática era a única forma de saber qual a voltagem ideal a ser aplicada ao paciente e justificou que a benesse era acalmar o paciente após a realização do procedimento. 
A médica, chocada com os tratamentos expostos em plenária, questiona ao diretor do hospital a real validade e consequências geradas à vida humana, e é ignorada pelo médico que, praticamente, impõe que ela realize os procedimentos que haviam sido explicitados. Ao haver a recusa da médica em utilizar aqueles procedimentos, lhe é proposto o trabalho no setor de terapia ocupacional do hospital.

Ao chegar no setor, encontra-o desorganizado e pede ajuda dos funcionários que lá laboravam para organizá-lo e modificá-lo. Apesar de não haver recursos suficientes que fomentassem o setor, a doutora Nise da Silveira passou a humanizar o tratamento dos pacientes por meio da arte, como forma de melhora no quadro destes. A melhora é devidamente comprovada no transcorrer do filme, inclusive no próprio comportamento daqueles que se submeteram à terapia ocupacional.

Assim, a psiquiatra torna-se a pioneira no Brasil na realização deste tratamento. Os pacientes que participaram da terapia ocupacional foram os esquizofrênicos. Diante desta alternativa, que com o passar do tempo passou a render bons frutos, os médicos do hospital, que discordavam desta técnica, excluíram a doutora Nise.

Dentro do contexto histórico de 1944, nas dependências do Hospital Engenho Doce, a única médica que se preocupava com a questão humanitária dos pacientes, do tratamento por intermédio do afeto e da arte, era a doutora Nise da Silveira, que proporcionou uma mudança e uma melhora na vida dos pacientes que foram por ela tratados.

Sobre os tratamentos ministrados aos pacientes psiquiátricos, apenas com o fim do eletrochoque, por exemplo, é que passaram a ser mais humanizados, conforme bem-relataram Lüchmann e Rodrigues (2007, p. 402). Isto ocorreu por meio de uma manifestação conhecida como Movimento dos Trabalhadores da Saúde Mental: "As reivindicações giram em torno de aumento salarial, redução de número excessivo de consultas por turno de trabalho, críticas à cronificação do manicômio e ao uso do eletrochoque, melhores condições de assistência à população e pela humanização dos serviços."

Assim, o que se observa deste procedimento é que se assemelha à tortura, o que era deveras comum na realidade do hospital no decorrer do filme, e os tratamentos degradantes, que, além do já citado, incluem os maus-tratos de forma geral, realmente como uma forma de "desumanização" do ser humano.

O que chama atenção na película, que faz com que se direcione ao mundo jurídico, é justamente relacionar a evolução dos tratamentos empregados aos pacientes acometidos de problemas mentais com as legislações brasileiras e internacionais, que passaram a dar importância ao ser humano como ser único.

Depreende-se uma real evolução no quesito tratamento ambulatorial dos pacientes com base na própria legislação, como ocorreu na modificação dos hospitais psiquiátricos. De modo a demonstrar esta mudança, tem-se o fim dos tratamentos que se assemelhavam à tortura, como o eletrochoque, bem como o fim de técnicas que não traziam a cura aos pacientes, como a lobotomia, por exemplo. 
Além disso, há uma mudança nos próprios hospitais psiquiátricos, ou manicômios (como eram antigamente considerados), pois havia a existência de verdadeiras celas separando os setores do hospital, como é bem-representado no filme quando expõe a realidade da época, quando os pacientes eram tratados como presos, sem praticamente nenhum direito ou garantia, e não como pacientes mentais, que necessitavam de cuidados específicos.

No mesmo contexto do filme, em apenas um recorte temporal distinto, o que se observou foi que em alguns hospitais do Brasil, em específico a Casa de Repouso de Guararapes, possuía o mesmo histórico de maus-tratos aos pacientes, como bem foi relatado no caso Ximenes Lopes versus Brasil, que tramitou perante a Corte Interamericana de Direitos Humanos.

Em breve relato do caso, os irmãos gêmeos Cosme e Damião eram acometidos de doenças mentais. Damião, por várias crises, precisou ser internado na Casa de Repouso de Guararapes, e em um desses internamentos a mãe do paciente narrou:

Cambaleando, com as mãos amarradas para trás, roupa toda estragada, a mostrar a cueca, corpo sujo de sangue, fedia a urina, fezes e sangue podre. Nas fossas nasais bolões de sangue coagulado. Rosto e corpo apresentavam sinais de ter sido impiedosamente espancado (PAIXÃO, 2007, p. 5).

Ocorre que na situação de maus-tratos ao paciente e posterior óbito, relatada em todos os internamentos de Damião, existia uma forma de tutelar os Direitos Humanos, feridos pelo tratamento demandado aos pacientes, fazendo com que o quadro de desumanização do tratamento fosse revertido, que era o caso da violação de Direitos Humanos.

Para isso, o meio jurídico, após todas as investigações realizadas em âmbito doméstico, foi a denúncia à Corte Interamericana de Direitos Humanos, diferente do contexto histórico retratado no filme "Nise", tempo em que não havia um reconhecimento de tais direitos. Assim, para vislumbrar a proteção no caso de Damião, foi necessária uma evolução legislativa no quesito tratamento de pacientes psiquiátricos e dos próprios direitos humanos.

\section{Evolução Legislativa}

Para que se possa realizar um paralelo com a realidade retratada na película "Nise - no coração da loucura" e o aspecto jurídico, foram utilizados os métodos histórico e indutivo, com uma análise da evolução legislativa no que diz respeito à pessoa.

Inicialmente será feito um estudo tratando da evolução da capacidade da pessoa, como bem-retratado no longa-metragem em seus minutos iniciais, quando o doutor César (Michel Bercovitch), em palestra, destaca que os pacientes mentais sofrem de total incapacidade para exercer quaisquer atos da vida civil.

A história passava-se no contexto legislativo vigente à época da Constituição Polaca (1937) e do Código Civil de 1916, no ano de 1944. Em um contexto jurídico distinto, portanto, do que hoje vivemos, partindo, assim, de uma Constituição outorgada por Vargas até a constituição cidadã, promulgada em 1988 e de um Código Civil voltado para o patriarcalismo e o patrimonialismo, e uso de termos considerados arcaicos hodiernamente a um Código Civil, hoje mais abrangente, pois releva o indivíduo em consonância com o Estatuto da Pessoa com Deficiência. 
Do mesmo modo, o que se depreende é que o paciente com deficiência mental passou a ter mais defesas no âmbito do Direito, principalmente no que se refere aos Direitos Humanos. Afinal, demonstra-se, de forma clara, no filme, como os pacientes eram tratados pelos médicos, que utilizavam o Hospital Psiquiátrico Engenho Doce como verdadeiro laboratório humano, com arcabouço em tratamentos desumanos, oriundos de exemplos de avanço dos países europeus e norte-americanos, que indicava os procedimentos da lobotomia e do eletrochoque.

Além disso, é importante destacar a própria evolução, garantias e tutelas dadas pelo Direito à saúde mental propriamente dita, ressaltando, principalmente, as legislações dos anos 1990 em diante e a importância do caso Ximenes Lopes na Corte Interamericana de Direitos Humanos.

\subsection{Capacidade: uma Análise da Pessoa com Deficiência}

Para que se inicie o breve estudo acerca da capacidade, faz-se necessário realizar um histórico acerca da questão da deficiência. Como berço civilizatório de análise da deficiência de modo mais abrangente, destacam-se alguns países:

Nos primórdios da civilização grega, a ação do Estado convergia para uma política de extermínio. Crianças espartanas e atenienses com deformações, bem como pessoas inúteis, tinham de ser mortas quando a cidade estivesse sitiada. Na Índia antiga, pessoas deficientes e doentes incuráveis eram atiradas no rio Ganges.

Igualmente, condutas nesse sentido estão retratadas na Idade Média, onde os surdos não teriam acesso à salvação, pois entendiam que a fé vinha de ouvir a palavra de Deus. Platão, buscando a forma de fortalecimento do Estado, defendia que os homens defeituosos deveriam se unir, o mais raro possível, com as mulheres defeituosas e seus filhos expostos a fim de padecerem. Também Aristóteles, em sua obra $A$ Política, retrata que a eugenia era defendida para sugerir que crianças recém nascidas, portadoras de más formações deveriam ser expostas ao acaso. Já os romanos, na Lei das XII Tábuas, quando tratam do pátrio poder na Tábua IV, estabeleciam que o filho monstruoso fosse morto imediatamente.

Assim, vemos essa política de extermínio e exclusão, adotada por gregos e romanos, avançar pelo Estado Medieval até a formação e consolidação do Estado Moderno, considerando o deficiente como civilmente morto, porque não tinha o direito de ter direito.

\section{(...)}

Contudo, os Hindus trabalhavam a segunda hipótese, a da inclusão dos deficientes, acreditando na sensibilidade interior das pessoas portadoras de deficiência visual, destinadas ao sacerdócio. Ainda, os Atenienses implantavam, para os heróis de guerra e suas famílias, uma espécie de previdência social (SILVA, 2009, p. 115).

Em um avanço legislativo, o marco é a Declaração Universal de Direitos Humanos (1948), promulgada no contexto pós Segunda Guerra Mundial. Norberto Bobbio (2004, p. 31-32) traz em sua obra "A era dos direitos", que houve uma individualização do ser humano pós Declaração de 1948, passando a tratar o indivíduo de forma una, respeitando suas diferenças, seja homem, mulher ou deficiente, destacando, entre várias Declarações, a Declaração dos Direitos do Deficiente Mental, de 1971. 
Antes de passarmos ao estudo deste documento internacional, em capítulo específico, todavia, faz-se mister analisar o contexto do Código Civil de 1916 e da Constituição de 1937, para perquirir se o Brasil ratificou ou não a Declaração e quais as consequências jurídicas no ordenamento brasileiro.O Código Civil de 1916 sofreu influência do Código francês de 1804 e do alemão de 1986 em sua elaboração, adotando-se deles várias concepções mormente em relação às pessoas, na parte geral, conforme Carlos Roberto Gonçalves (2017, p. 38).

Nesse contexto, destaca Venosa $(2017$, p. 158) acerca da capacidade e personalidade no âmbito do antigo Código Civil: "Quando o Código de 1916 dispunha, no art. 2º, que o homem era capaz de direitos e obrigações, entrosava o conceito de capacidade com o de personalidade. A capacidade é a medida da personalidade".

Primeiro, depreende-se que apenas o homem era capaz de direitos e obrigações, excluindo-se a mulher, ou os escravos (que eram considerados como res), modificado no contexto do Código Pátrio, que considera "toda pessoa" em seu artigo 10, ${ }^{1}$ como sujeito de direitos, logo, dotado de capacidade.

Destaca-se que o Código Civil pátrio trata de duas capacidades: a de direito, aquisição ou gozo, que é a de ser sujeito de direitos (esta todas as pessoas necessariamente têm), e a de fato, exercício ou ação, que é a de que o sujeito tem de contrair direitos e obrigações na ordem civil. Antes do advento do Estatuto da Pessoa com Deficiência, a capacidade relacionava-se com idade e estado de saúde da pessoa; após, houve modificações no texto legal, conforme se verá ao fim da evolução legislativa do Código Civil.

Cristiano Chaves de Farias e Nelson Rosenvald lembram que a capacidade, de fato, é própria da pessoa que nasce com vida e estaria atrelada, por sua vez, a condições biológicas e legais (FARIAS; ROSENVALD, 2016, p. 321)

Após o breve introito, realizando um comparativo com a película ora analisada, o Código de 1916 trazia, em seu artigo 50, inciso II, como absolutamente incapaz os "loucos de todo gênero". É importante salientar que à época da promulgação do código, bem como no contexto do filme (ano de 1944), não havia uma noção jurídica do conceito de saúde mental, e os pacientes que eram acometidos por algum problema mental eram considerados loucos. Nesse sentido, destaca Beviláqua (apud VENOSA, 2017, p. 158) que "apontara, na época, não ser necessária uma definição rigorosa de alienação mental. A explanação do festejado mestre já admitia a falta de técnica da expressão do antigo diploma".

Em sentido contrário ao do autor, apresentamos o pensamento da professora Maria Helena Diniz, que considera insanidade mental e loucura formas de se medir a incapacidade da pessoa:

Por isso, entendemos, andou bem a legislação civil em não enumerar as formas de alienação mental, pois obrigaria o intérprete civil a exigir da perícia a dificílima diagnose de cada caso. Ora, o direito deve contentar-se com um critério prático: a simples afirmação de um estado de enfermidade ou deficiência mental, que reclame intervenção protetora,

Artigo 1ํ-Toda pessoa é capaz de direitos e deveres na ordem civil. 
visto que a pessoa tornou-se absolutamente incapaz de prover aos próprios interesses, de dirigir sua vida, de exercer seus direitos, com discernimento, por ser doente ou por sofrer qualquer perturbação das faculdades mentais.

A anomalia psíquica é, portanto, qualquer doença que compreende não só o estado fronteiriço entre a sanidade e a insanidade mental como também a loucura (2014, p. 175).

Ousa-se discordar do pensamento da renomada autora, tendo em vista que as anomalias psíquicas são dotadas de tratamento, e a depender do nível em que se encontre não é fator determinante para definir a pessoa humana como totalmente incapaz de exercer os atos da vida civil, como bem-destaca o Estatuto da Pessoa com Deficiência.

Para isto, deve ser analisado caso a caso, para que se chegue a um diagnóstico de que a pessoa é ou não capaz ou incapaz de exercer os atos da vida civil. Nesse espeque, a doutrina civilista moderna critica o termo em desuso "loucura". Colaciona-se, por oportuno, o entendimento de Caio Mário da Silva Pereira:

As deficiências podem ser mais ou menos profundas: alcançar a totalidade do discernimento; ou, ao revés, mais superficiais, aproximar o seu portador da plena normalidade psíquica. O direito observa estas diferenças, e em razão delas gradua a extensão da incapacidade, considerando, de um lado, aqueles que se mostram inaptos para o exercício dos direitos, seja em consequência de um distúrbio da mente, seja em razão da total inexperiência, seja em função da impossibilidade material de participação no comércio civil; de outro lado, os que são mais adequados à vida civil, portadores de um déficit psíquico menos pronunciado, ou já mais esclarecidos por uma experiência relativamente ponderável (2017, p. 228-229).

Desta forma, ressalta-se que ocorreu uma mudança no tratamento dado à pessoa portadora de deficiência. Na vigência do Código de 1916 os portadores de alguma doença mental eram tratados como loucos de qualquer espécie, havendo uma modificação no Código de Reale hoje vigente, no sentido de tratar de forma humanitária o detentor de doença mental, no que diz respeito às questões de capacidade e incapacidade, principalmente.

Nesse norte, Pablo Stolze Gagliano destaca que Nina Rodrigues já criticava duramente a expressão "loucos de todo o gênero" no Código Civil de 1916 (GAGLIANO; FILHO, 2016, p. 146).

É importante destacar legislações internacionais e nacionais que tratam do assunto. É inexorável a correlação da pessoa portadora de doença mental com a pessoa com deficiência, pois o termo "pessoa com deficiência" abrange a "pessoa com deficiência mental". Esta prerrogativa é destacada em documentos internacionais (Convenção Interamericana para a eliminação de todas as formas de discriminação contra as pessoas portadoras de deficiência ou a Declaração dos Direitos do Deficiente - Convenção da Guatemala), bem como no atual Estatuto da Pessoa com Deficiência.

Da Assembleia Geral da Declaração dos Direitos do Deficiente, destaca-se:

Recordando os princípios da Declaração Universal dos Direitos Humanos, dos Acordos Internacionais dos Direitos Humanos, da Declaração dos Direitos da Criança e da Declaração dos Direitos das Pessoas Mentalmente Retardadas, bem como os padrões já estabelecidos para o progresso social nas constituições, convenções, recomendações e reso- 


\section{Democracia}

luções da Organização Internacional do Trabalho, da Organização Educacional, Científica e Cultural das Nações Unidas, do Fundo da Criança das Nações Unidas e outras organizações afins. (...)

Enfatizando que a Declaração sobre o Desenvolvimento e Progresso Social proclamou a necessidade de proteger os direitos e assegurar o bem-estar e reabilitação daqueles que estão em desvantagem física ou mental,

Tendo em vista a necessidade de prevenir deficiências físicas e mentais e de prestar assistência às pessoas deficientes para que elas possam desenvolver suas habilidades nos mais variados campos de atividades e para promover portanto quanto possível, sua integração na vida normal, (...)

PROCLAMA esta Declaração dos Direitos das Pessoas Deficientes e apela à ação nacional e internacional para assegurar que ela seja utilizada como base comum de referência para a proteção destes direitos:

1 - 0 termo "pessoas deficientes" refere-se a qualquer pessoa incapaz de assegurar por si mesma, total ou parcialmente, as necessidades de uma vida individual ou social normal, em decorrência de uma deficiência, congênita ou não, em suas capacidades físicas ou mentais (GUATEMALA, 2016).

Ademais, sobressai o Decreto n. 3.956, de 2001, que promulga a Convenção Interamericana para a Eliminação de Todas as Formas de Discriminação contra as Pessoas Portadoras de Deficiência, no Brasil, em seu artigo 10 que traz que, "o termo 'deficiência' significa uma restrição física, mental ou sensorial, de natureza permanente ou transitória, que limita a capacidade de exercer uma ou mais atividades essenciais da vida diária, causada ou agravada pelo ambiente econômico e social".

Nesse sentido, em termos conceituais e com base em uma interpretação conforme a Constituição, preceitua Silva (2009, p. 121) que a Convenção da Guatemala é a que deve ser levada em consideração, tendo em vista tratar do assunto de forma mais geral.

Perpassando pela evolução legislativa do Código Civil de 1916, vigente à época do longa-metragem ora retratado, pelo Código Civil de 2002 e por documentos internacionais com o fito de conceituar o termo "deficiente", é de suma importância saber como a legislação específica atualmente vigente trata a questão do deficiente mental e qual a proteção a ele dada.

Para isto, faz-se necessária a análise do Estatuto da Pessoa com Deficiência, de 6 de juIho de 2015. Inicialmente, faz-se mister ressaltar os seguintes artigos:

Art. 2 - Considera-se pessoa com deficiência aquela que tem impedimento de longo prazo de natureza física, mental, intelectual ou sensorial, o qual, em interação com uma ou mais barreiras, pode obstruir sua participação plena e efetiva na sociedade em igualdade de condições com as demais pessoas.

Art. 25. Os espaços dos serviços de saúde, tanto públicos quanto privados, devem assegurar o acesso da pessoa com deficiência, em conformidade com a legislação em vigor, mediante a remoção de barreiras, por meio de projetos arquitetônico, de ambientação de interior e de comunicação que atendam às especificidades das pessoas com deficiência física, sensorial, intelectual e mental (GONÇALVES, 2017). 
Do artigo 2ำ não se vê nenhuma mudança pontual do conceito de pessoa com deficiência. $O$ artigo 25, contudo, mostra-se deveras importante, pois trata da questão da remoção de barreiras por meio de projetos e ambientações, o que não era uma realidade dos hospitais psiquiátricos no Brasil, como bem-retratado no Engenho Doce (hospital em que passa o filme), cujas divisões de alas hospitalares eram por meio de grades, como uma verdadeira prisão, e esta quebra de paradigmas veio de forma expressa no Estatuto e em outros diplomas normativos, analisados, oportunamente, posteriormente.

O Estatuto trouxe modificações mais expressivas no que respeita à pessoa com deficiência para a prática dos atos da vida civil, revogando os incisos I, II e III, do artigo 3ㅇ do Código Civil pátrio, que tratava daqueles que possuíam enfermidade ou deficiência mental que não tivessem o necessário discernimento para a prática dos atos da vida civil e daqueles que, por caráter transitório, não podiam exprimir sua vontade, deixando apenas a previsão do inciso I, em forma de caput, ao tratar dos menores de 16 anos.

Desta maneira, o que se nota é uma verdadeira modificação em termos de capacidade no que se refere às pessoas portadoras de deficiência, afinal, o Código Civil de 1916 tratava os pacientes com deficiência mental como loucos de todo gênero; em seguida, considerados absolutamente incapazes, nos termos do artigo 3으, do Código Civil de 2002, já com o termo deficiente mental, trazido pelos documentos internacionais e, por fim, no que diz respeito à capacidade, deixaram de ser considerados absolutamente incapazes.

\subsection{Análise dos Tratamentos à Luz da Dignidade da Pessoa Humana}

Inicialmente é importante relatar a importância dos Direitos Humanos como elementos de proteção da vida humana, afinal, antes de serem tutelados de forma positivada nos documentos internacionais, já eram elementos intrínsecos ao ser humano. Assim, destaca-se o pensamento de Barroso (2010, p. 10-11):

Ao longo do tempo, consolidou-se a convicção de que nos casos difíceis, para os quais não há solução pré-pronta no direito posto, a construção da solução constitucionalmente adequada precisa recorrer a elementos extrajurídicos, como a filosofia moral e a filosofia política. E, dentre eles, avulta em importância a dignidade humana. Portanto, antes mesmo de ingressar no universo jurídico, positivada em textos normativos ou consagrada pela jurisprudência, a dignidade já desempenhava papel relevante, vista como valor pré e extrajurídico, capaz de influenciar o processo interpretativo. É fora de dúvida, todavia, que sua materialização em documentos constitucionais e internacionais sacramentou o processo de juridicização da dignidade, afastando o argumento de que o Judiciário estaria criando normas sem legitimidade democrática para tanto.

Ultrapassado este entendimento inicial, passa-se a tratar o contexto do filme, que ocorre no ano de 1944, em plena Segunda Guerra Mundial, em que aconteciam os atos de atrocidade contra os judeus na Alemanha nazista - o holocausto -, bem como não havia a noção do que hoje se conhece por tratamento humano degradante ou tortura.

$O$ relato da película mostra a forma desumana de tratamento dada aos pacientes de forma geral: maus-tratos, tortura, além da utilização de técnicas arcaicas, como lobotomia e eletrochoque, em que nada auxiliava na melhora dos pacientes acometidos por doenças mentais. Faziam, portanto, verdadeiros testes, em que os pacientes eram as cobaias. 
A Constituição de 1937 era a que vigia à época do recorte temporal do início da película. O que se via do contexto do hospital era que praticamente não se tratava de um ambiente hospitalar, mas sim de uma prisão, pois os pacientes viviam em locais divididos por grades, que lembravam celas de presídios. Além disso, viviam como verdadeiros prisioneiros, à mercê dos enfermeiros e médicos que utilizavam da força como o único elemento de controle ou de poder ante aqueles que estavam à margem da sociedade.

A chamada Constituição Polaca trazia, no capítulo de Direitos e garantias individuais, em seu artigo 122, algumas prerrogativas inerentes à pessoa; todavia, o rol não era tão extenso quanto no atual artigo 50 da Carta Constitucional de 1988. Destaca-se da legislação vigente à época que: "não haverá penas corpóreas perpétuas", não se falando em vedação à tortura ou maus-tratos, amplamente difundidos na atualidade; afinal, não havia uma tutela mais veemente de como se tratava isto antes do contexto do fim da Segunda Guerra Mundial. Nesse sentido:

Após a 2a Guerra Mundial, a idéia de dignidade da pessoa humana migra paulatinamente para o mundo jurídico, em razão de dois movimentos. O primeiro foi o surgimento de uma cultura pós-positivista, que reaproximou o Direito da filosofia moral e da filosofia política, atenuando a separação radical imposta pelo positivismo normativista. O segundo consistiu na inclusão da dignidade da pessoa humana em diferentes documentos internacionais e Constituições de Estados democráticos (BARROSO, 2010, p. 4).

Os maus-tratos, tortura e a utilização de métodos cirúrgicos eram constantes na vida dos pacientes. Na maioria das vezes os médicos testavam as técnicas importadas, sem pensar no bem-estar do paciente ou nas consequências geradas no tratamento. Esse pensamento modificou-se, ainda que minimamente, quando a doutora Nise da Silveira (interpretada por Glória Pires), passou a humanizar o tratamento por meio da Terapia Ocupacional com os doentes mentais, sem levar em consideração as técnicas consideradas "mais modernas" para a época, passando a tratar os pacientes como pessoas normais e não como "loucos".

Esta ideia de vedação à tortura e ao tratamento degradante ao ser humano, somente veio tomar forma e ter as devidas proporções em âmbito mundial no pós Segunda Guerra Mundial, com a proclamação, pela Organização das Nações Unidas, da Declaração Universal de Direitos Humanos de 1948. Nesse sentido,

O movimento de internacionalização dos direitos humanos constitui um movimento extremamente recente na história, surgindo, a partir do pós-guerra, como resposta às atrocidades e aos horrores cometidos durante o nazismo. Se a 2a Guerra Mundial significou a ruptura com os direitos humanos, o Pós-Guerra deveria significar a sua reconstrução. É neste cenário que se desenha o esforço de reconstrução dos direitos humanos, como paradigma e referencial ético a orientar a ordem internacional contemporânea (PIOVESAN, 2007, p. 36-37).

A partir do contexto ora retratado, devidamente ratificado e seguido pela Ordem Constitucional de 1988, os direitos humanos passaram a ser inerentes a cada pessoa, vedando-se, no artigo 5 o, quaisquer tratamentos degradantes ou tortura.Partindo dessa premissa, numa

Lobotomia e eletrochoque (eletroconvulsioterapia). 
análise no que diz respeito às pessoas com deficiência, vê-se que a ordem jurídica constitucional vigente buscou tutelar de forma específica as pessoas portadoras de deficiência, abrangendo-as de todas as formas e dando um tratamento especial, como reverbera Silva:

Como já visto, a Magna Carta de 1988 representa importante marco vivificador dos direitos afetos às pessoas portadoras de deficiência, uma vez que preconiza que a proteção desse grupo de pessoas deve ser ampla e irrestrita, constitucionalizando, inclusive, tendências dos principais documentos internacionais de direitos humanos (SILVA, 2009, p. 118).

Logo, do pressuposto da evolução constitucional à proteção aos direitos humanos, em específico das pessoas com deficiência, observa-se que o Direito Internacional e seus documentos foram de grande importância, assim como a nova visão dada às pessoas com deficiência e aos tratamentos realizados. Além disso, destaca-se o entendimento da Corte Suprema dos Estados Unidos ao exarar entendimento, considerando "violadora da dignidade humana a execução de deficientes mentais" (BARROSO, 2010, p. 6), o que acaba por ressaltar a importância do fim dos tratamentos desumanos e degradantes aplicados aos pacientes com deficiência.

Nesse mesmo sentido, a Declaração de Pessoas com Deficiência, em 2006, passou a incorporar os termos da Declaração Universal de Direitos Humanos de 1948. Realizando uma análise comparativa entre a Declaração e a realidade dos pacientes retratadas no filme, vê-se que algumas condutas seriam reprovadas, como bem-destaca o artigo 50 da Declaração de 1948, que aduz: "Ninguém será submetido à tortura nem a tratamento ou castigo cruel, desumano ou degradante".

Acerca do artigo referido, a personagem principal da história tentou de todos os modos fazer com que os pacientes por ela tratados fossem reconhecidos como pessoas de verdade, numa tentativa de libertação dos problemas mentais pela arte. Isto se adequa ao artigo 19 da Declaração Universal, ao garantir o direito de liberdade de opinião e expressão.

Neste ponto, analisa-se que vigia à época questões referentes ao "louco de todo gênero" e à incapacidade absoluta dos doentes mentais; logo, os médicos, juntamente com as famílias, eram os responsáveis pela escolha do tratamento dos pacientes.

Doutora Nise garantiu o direito de expressão dos pacientes por meio da arte, todavia este direito foi, algumas vezes, rechaçado por outros médicos que não acreditavam nas meIhoras apresentadas, como ocorreu com o personagem Lúcio (Roney Villela), que foi submetido ao procedimento de lobotomia e sua liberdade de expressão foi tolhida, pois, como consequência da cirurgia, ficou apático às emoções, não podendo mais produzir suas esculturas.

O rol de direitos humanos fundamentais, fomentado pela Constituição Federal de 1988, principalmente no artigo $5^{\circ}$, destaca os incisos III, XLIII no que se refere à vedação à tortura. $\mathrm{O}$ texto constitucional foi fortemente influenciado pela Declaração Universal de Direitos Humanos.

Por fim, o deficiente mental deverá ser tratado como ser humano, e, nesse sentido, já na ordem constitucional vigente, tem-se que:

A possibilidade de exercício desses direitos e garantias individuais sintetiza a condição de ser humano, pois o torna distinto como ser racional único e insubstituível e, portanto, provido de dignidade e de autodeterminação. 
Trata-se, como bem salientado por Célia Rosenthal Zisman, da respeitabilidade mínima, "que não depende nem mesmo do caráter da pessoa, [que] consiste na própria consideração da sua existência, pelos seus semelhantes, coincidindo então com o conceito de dignidade, visto que se efetiva com a preservação dos direitos fundamentais. A respeitabilidade mínima em relação ao homem não depende, portanto, de seus feitos, ou ainda, de sua idade, condição social, ascendência ou grau de hierarquia. Trata-se do tratamento digno, ao qual qualquer pessoa tem direito, no plano universal (SANTORO FILHO, 2012, p. 25-26).

No contexto hodierno em relação ao tratamento dos pacientes acometidos de problemas mentais, portanto, os quesitos referentes à dignidade da pessoa humana e ao comprometimento com os direitos humanos fundamentais obrigatoriamente devem ser levados em conta. Afinal, cada pessoa deve ser considerada única e insubstituível.

Nesse diapasão, é importante ressaltar o caso Ximenes Lopes versus Brasil, que tramitou na Corte Interamericana de Direitos Humanos, quando foi denunciado o caso de tortura na Casa de Repouso de Guararapes no Brasil por violação de diversos direitos, principalmente maus-tratos e tortura, em que todas as vezes que o país foi instado a se manifestar quedou-se inerte.

Em sede de relatório de admissibilidade do processo na Corte, foi "concluindo que a petição contra o Estado brasileiro era admissível no caso da morte de Damião, pela violação de seus direitos à integridade pessoal, à vida, à proteção judicial e às garantias judiciais, todos assegurados na Convenção Americana" (PAIXÃO, 2007, p. 9).

No que respeita à "hospitalização de Damião, a mesma ocorreu em condições desumanas e degradantes, com violação à sua integridade pessoal, resultando em seu assassinato" (PAIXÃO, 2007, p. 9). O relatório também fixou prazo para cumprirem algumas recomendações, que o Brasil efetivou. Ainda como evolução do tratamento, considera Paixão (2007, p. 14-15) que:

A Corte foi clara na fixação do dever dos Estados em assegurar atendimento médico eficaz às pessoas portadoras de deficiência mental. Neste particular, foi reconhecido também que o respeito à autonomia das pessoas em relação ao tratamento de saúde, nesses casos, não é absoluto, já que a própria necessidade do paciente pode exigir algumas vezes a adoção de medidas sem seu consentimento. Foi ressaltado, todavia, o dever de se aplicar a presunção de que as pessoas portadoras desse tipo de deficiência são capazes de expressar sua vontade, a qual deve ser respeitada pelo pessoal médico e pelas autoridades. Em relação ao respeito à dignidade do portador de sofrimento mental durante seu tratamento, a Corte recorreu aos Princípios para a Proteção dos Doentes Mentais e para a Melhoria do Atendimento de Saúde Mental, das Nações Unidas.

Esse pensamento confirma as teses de humanização do tratamento, além de toda a evolução legislativa que ocorreu para beneficiar os pacientes que possuem problemas mentais, garantindo o cumprimento e a prevalência dos direitos humanos conforme a decisão da Corte, inclusive passando a responsabilizar o Estado com base em infração ao direito à vida, principalmente. Ademais, considerava-se como "violado o direito à integridade psíquica e moral dos familiares das vítimas em virtude do sofrimento adicional que passaram" (PAIXÃO, 2007, p. 15). 
A título de reparação, o caso trouxe deveres do Estado para com as partes lesadas (Ximenes Lopes e familiares), destacando-se que: fossem investigados os responsáveis pelo fato dentro de prazo razoável, o pagamento de indenização para Albertina Viana Lopes e Irene Ximenes Lopes Miranda, além de estabelecer para o Brasil a obrigação de capacitação dos profissionais da saúde que lidam com pacientes mentais.

A indenização foi devidamente paga pelo Brasil, restando solvida a questão indenizatória. Deparava-se, todavia, com o problema do cumprimento da obrigação penal, esbarrando na dificuldade da execução das sentenças da Corte Interamericana de Direitos Humanos no Brasil.

Concluiu-se acerca da sentença que, apesar da condenação no âmbito da esfera civil ser de fácil estabelecimento, até pela rubrica orçamentária específica na Secretaria de Direitos Humanos, hoje Ministério dos Direitos Humanos, o mesmo não se analisa no que assenta ao restante da condenação, em razão, principalmente, do vácuo legislativo com as diretrizes para o cumprimento, como se depreende do trecho que segue:

A sentença da Corte ora analisada inicia um novo momento para os significados e para força dos direitos humanos. O fato de o Brasil ter sido condenado por violar os direitos de um portador de sofrimento mental lança luz para a necessidade cada vez mais urgente de se repensar as formas como o Direito lida com o sofrimento mental. Institutos como a interdição, as medidas de segurança, etc., precisam ser repensadas para que o princípio de proteção desses sujeitos- fortalecido pela condenação - seja respeitado em cada dimensão da vida desses sujeitos (PAIXÃO, 2007, p. 20).

Tais fatos relatados no caso ilustrativo e na análise do direito no contexto do filme, coadunam-se com o rol de valores intrínsecos à pessoa humana, elencados por Barroso (2010, p. 22-23), e observa-se: direito à vida, direito à igualdade, direito à integridade física; e destaca-se o direito à integridade moral ou psíquica, que justamente faz com que não ocorram condutas que visem a agravar ou lesar a dignidade da pessoa humana.

\section{Saúde Mental: legislação e novos tratamentos}

Incialmente, é importante destacar que no âmbito do direito civil e penal não existe nenhum conceito do que seria "doença mental" (SANTORO FILHO, 2012, p. 21). Logo, a área do direito é ausente em termos conceituais, limitando-se, como já foi visto, a tratar das questões de capacidade, principalmente no âmbito cível.

Os quesitos referentes à capacidade também se relacionam com o direito penal dentro do ordenamento jurídico brasileiro, aduzindo-se na chamada inimputabilidade penal, presente no artigo 26, CP, desde que atenda aos requisitos do conceito de pessoa com deficiência.

No que respeita ao quesito legislação, que genericamente abrange questões constitucionais relacionadas aos direitos humanos fundamentais, civil e processual civil, no que concerne à capacidade e no que se refere à inimputabilidade penal, não se pode deixar de levar em consideração a legislação específica sobre o tema saúde mental. 
Para isso, será realizada uma breve análise histórica de algumas legislações de modo pontual, para demonstrar a importância que o tema passou a ter com o passar dos anos. Destaca-se o primeiro documento acerca da reestruturação da Assistência Psiquiátrica dentro dos Sistemas Locais de Saúde, que foi a Declaração de Caracas, no ano de 1990, trazendo a permissão do uso de modelos alternativos de tratamento, o que incluía a terapia ocupacional.

No Brasil, destaca-se a Lei no 10.216/2001, que trata da proteção e direitos das pessoas portadoras de transtornos mentais e realiza um redirecionamento do modelo assistencial em saúde mental. Nesse sentido, ressalta o Ministério da Saúde (BRASIL, 2004, p. 20) que "a lei redireciona o modelo da assistência psiquiátrica, regulamenta cuidado especial com a clientela internada, por longos anos e prevê possibilidade de punição para a internação arbitrária ou desnecessária".

Ocorreu um aporte na evolução médica dos tratamentos até a chamada reforma psiquiátrica (criação dos Caps), ${ }^{3}$ devidamente subsidiada pelo SUS. Os internamentos dos chamados "loucos" eram realizados com um único intuito: o de segregar, opção que, com o passar dos anos, passou a dar lugar ao intento de integrar o indivíduo na sociedade.

O Caps veio para substituir os antigos manicômios. No país esta mudança iniciou-se na década de 70, observando-se uma mutação em comparação com o contexto do filme de, em média, 30 anos. Esta modificação de pensamento foi coroada com o texto constitucional de 1988 e a efetivação do SUS, a partir de que se estabeleceram novas condições institucionais para a saúde.

Nesse sentido, tem-se que a reforma psiquiátrica, baseada na Lei 10.216/01, assentou que:

De acordo com a proposta trazida pela Política Nacional de Saúde Mental, busca-se a substituição do modelo hospitalocêntrico e o resgate da cidadania ao portador de transtornos mentais, através da inclusão social, reinserção familiar e respeito aos seus direitos e liberdade, garantindo-lhe a livre circulação e interação com a comunidade (MINSTÉRIO..., 2010, p. 7).

Além do Caps, a Reforma Psiquiátrica dispõe sobre o serviço residencial terapêutico, baseado na Portaria MS 106/2000, bem como no Programa de volta para casa, com escopo na Lei 10.708/03. Ademais, observa-se uma verdadeira evolução nos tratamentos voltados às pessoas com deficiência mental.

No Estado do Rio Grande do Norte, no ano de 1995, foi promulgada a Lei Estadual no 6.758, que versa sobre a adequação dos hospitais psiquiátricos e dos leitos psiquiátricos em hospitais gerais, além de construção de unidades psiquiátricas. Tal instituto trouxe, em seu bojo, a estipulação de um prazo de seis anos para a reavaliação dos hospitais psiquiátricos no Estado e adequação às novas normas.

A Portaria GM no 106, de 11 de fevereiro de 2000, passou a destacar a necessidade da assistência integral em saúde mental por parte do Sistema Único de Saúde (SUS) e da humanização do atendimento psiquiátrico, bem como instituiu os Serviços Residenciais Terapêuticos em Saúde Mental no âmbito do SUS.

Centro de Atenção Psicossocial. 
A Portaria SNAS no 224, de 29 de janeiro de 1992, traz, em suas normas para o atendimento ambulatorial, a previsão no ponto 1.3 do atendimento grupal (grupo operativo, terapêutico, etc.), o qual foi inicialmente proposto pela doutora Nise da Silveira. Ademais, esta portaria "estabelece normas, proíbe práticas que eram habituais e define como co-responsáveis, à luz da Lei Orgânica da Saúde e pela fiscalização do cumprimento dos seus conteúdos" (BRASIL, 2004, p. 252).

Assim, observa-se que desde o início do recorte temporal (1944-2016) ocorreram modificações sérias e significativas no âmbito da legislação de saúde mental, ressaltando-se, inicialmente, uma preocupação mais abrangente no Código Civil, Código Penal, Constituição Federal de 1988, Declaração Universal de Direitos Humanos de 1948, Convenção Interamericana para a Eliminação de Todas as Formas de Discriminação contra as Pessoas Portadoras de Deficiência e Estatuto da Pessoa com Deficiência, para os pacientes propriamente ditos, no que diz respeito aos direitos e garantias individuais.

No âmbito da saúde mental, entretanto, após a Declaração de Caracas e as legislações brasileiras e do Estado do Rio Grande do Norte, passou-se a tratar o direito à saúde mental de outra forma, dando garantias e um tratamento mais digno e humano aos pacientes que possuem estes problemas. Destaca-se a retirada das grades que lembravam as celas, substituídas por leitos psiquiátricos, bem como com a possibilidade de tratamento em casa, subsidiado pelo SUS.

\section{Considerações Finais}

Diante do que se demonstrou, observa-se que ocorreu uma mudança no tratamento dos pacientes acometidos de deficiência mental. No que diz respeito aos hospitais, as "prisões" transformaram-se em leitos, inclusive no próprio Estado do Rio Grande do Norte, que, com a Lei Estadual, fez com que os hospitais psiquiátricos se adequassem às novas normas.

Em relação ao tratamento dos pacientes, realizando um paralelo com a história retratada, depreende-se que houve uma modificação brusca, pois se utilizava de maus-tratos e tortura, cujo único objetivo era o de fazer com que os pacientes ficassem submissos aos "tratamentos", e, no caso, era utilizada predominantemente a força, salvo a terapia ocupacional proposta pela doutora Nise da Silveira, que veio a começar uma desmistificação dos tratamentos psiquiátricos no país.

Desta realidade, passou-se a admitir tratamentos como a terapia ocupacional, bem como a utilização de medicamentos de forma mais terapêutica e humanizada nas possibilidades de perquirir a melhora dos que possuíam transtornos mentais, além das formas de integração dos deficientes mentais por meio da Reforma Psiquiátrica, utilizando-se o Caps e o Programa de volta para a casa, retirando a existência dos manicômios e os substituindo por leitos ou enquadrando nos requisitos da Reforma Psiquiátrica.

Ressalta-se, assim, a importância de visualizar, no filme, que retratava uma realidade arcaica de procedimentos realizados em pacientes mentais, devidamente amparados pela legislação da época, a possibilidade de acompanhar a evolução histórica e legislativa acerca do tema, constatando-se uma verdadeira reviravolta inclusiva nos tratamentos e quebra destes paradigmas inicialmente abordados. 


\section{Democracia}

Não se pode afirmar que este tratamento arcaico veio a influenciar a edição de leis que garantissem este tipo de tratamento ambulatorial, mas por meio da Portaria SNAS no 224, de 29 de janeiro de 1992, houve a previsão expressa deste tratamento mais humanitário aos pacientes, cujo intuito era substituir a previsão de tratamentos arcaicos e desumanos, como lobotomia e eletrochoque, inserindo tratamentos mais humanos, que realmente dessem à pessoa tratamento de um sujeito de direitos.

Em relação a questões referentes à capacidade, a expressão "louco de todo o gênero" foi devidamente execrada do Código em 2002, sendo os deficientes mentais ou intelectuais, desde 2009, considerados capazes, via Convenção sobre os Direitos das Pessoas com Deficiência, incorporada ao direito interno brasileiro por meio do Decreto Legislativo 186, de 9.7.2008 e com a promulgação dada pelo Decreto Executivo 6.949, de 25.8.2009. Finalmente, a Lei 13.146, de 6.7.2015 (Estatuto da Pessoa com Deficiência), regulamentou a Convenção para, indubitável e tardiamente, confirmá-los absolutamente capazes. No que diz respeito aos relativamente incapazes, ocupam hoje esta posição as pessoas que não conseguem expressar sua vontade por causa permanente e provisória. No rol dos incapazes hoje figuram somente os menores de 16 anos.

Nesse espeque, o que restou foi a curatela específica e as tomadas de decisão apoiadas, para, em situações excepcionais, serem utilizados pela pessoa com deficiência mental ou intelectual no seu interesse exclusivo e como forma de proteção, enterrando o conceito de interdição no sentido de privação de direitos.

Assim, ratifica-se o entendimento de Flávio Tartuce (2018, p. 132), que coloca nos termos de uma verdadeira "revolução na Teoria das incapacidades", ao se priorizar a dignidade-liberdade em detrimento da liberdade-vulnerabilidade.

Em suma, o que se vê é que ocorreu uma verdadeira humanização no tratamento dos pacientes, o que deve ser visto de modo extremamente positivo, devendo sempre as legislações brasileiras e internacionais aprimorarem os estudos acerca do tema, para que cada vez mais os tratamentos possam oferecer mais dignidade aos doentes mentais.

É importante avaliar o relevo do caso Ximenes Lopes, que foi um marco emblemático para a afirmação dos direitos humanos nos casos de tratamento de pacientes acometidos de problemas de saúde mental. De valor ímpar, foi mais um caso que passou a ofertar sentido à garantia desses direitos para pessoas que anteriormente não os tinham, como os internos na Casa de Repouso Guararapes (CE).

Por fim, o que se nota é que a humanização do tratamento dado aos pacientes mentais se mostra deveras relevante, tendo em vista que a vida humana não pode ser valorada, sendo, portanto, elemento essencial para mantê-la a existência de preceitos essenciais inerentes à dignidade da pessoa humana.

\section{REFERÊNCIAS}

BARROSO, Luís Roberto. A dignidade da pessoa humana no direito constitucional contemporâneo: natureza jurídica, conteúdos mínimos e critérios de aplicação. 2010. Disponível em: <https://www.luisrobertobarroso.com. br/wp-content/uploads/2010/12/Dignidade_texto-base_11dez2010.pdf>. Acesso em: 7 set. 2016.

BOBBIO, Norberto. A era dos Direitos. 9. ed. 7. reimpr. Rio de Janeiro: Elsevier, 2004. Disponível em: <http:// www.mprj.mp.br/documents/10227/14586286/a_era_dos_direitos.pdf>. Acesso em: 21 jul. 2016. 
BRASIL. Constituição dos Estados Unidos do Brasil (de 10 de novembro de 1937). Disponível em: <http://www. planalto.gov.br/ccivil_03/Constituicao/Constituicao37.htm>. Acesso em: 23 jul. 2016. Lei no 10.216 de 6 de abril de 2001. Disponível em: <http://www.planalto.gov.br/ccivil_03/leis/ LEIS_2001/L10216.htm>. Acesso em: 28 jul. 2016.

. Lei no 10.406, de 10 de janeiro de 2002. Disponível em: <http://www.planalto.gov.br/ccivil_03/ leis/2002/L10406.htm>. Acesso em: 21 jul. 2016.

Lei no 13.146, de 6 de julho de 2015. Disponível em: <http://www.planalto.gov.br/ccivil_03/_Ato20152018/2015/Lei/L13146.htm>. Acesso em: 23 jul. 2016.

Legislação em saúde mental: 1990-2004. 5. ed. Brasília: Ministério da Saúde; Secretaria-Executiva; Secretaria de Atenção à Saúde, 2004.

DINIZ, Maria Helena. Curso de Direito Civil brasileiro. Volume 1: teoria geral do direito civil. 31. ed. São Paulo: Saraiva, 2014.

ESTADOS UNIDOS. Declaração dos Direitos das Pessoas Deficientes. Disponível em: <http://portal.mec.gov.br/ seesp/arquivos/pdf/dec_def.pdf>. Acesso em: 23 jul. 2016.

FARIAS, Cristiano Chaves de; ROSENVALD, Nelson. Curso de Direito Civil: parte geral e Lindb. 14. ed. Salvador: Juspodivm, 2016.

GAGLIANO, Pablo Stolze; FILHO, Rodolfo Pamplona. Novo curso de direito civil. São Paulo: Saraiva, 2016.

GONÇALVES, Carlos Roberto. Direito Civil Brasileiro. Volume 1: parte geral - de acordo com o novo Código Civil e o Estatuto da Pessoa com Deficiência. 15. ed. São Paulo: Saraiva, 2017.

GUATEMALA. Convenção Interamericana para a Eliminação de Todas as Formas de Discriminação contra as Pessoas Portadoras de Deficiência. Disponível em: <http://www.planalto.gov.br/ccivil_03/decreto/2001/d3956. htm>. Acesso em: 23 jul. 2016.

LÜCHMANN, Ligia Helena Hahn; RODRIGUES, Jefferson. O movimento antimanicomial no Brasil. 2007. Disponível em: <http://www.scielosp.org/pdf/csc/v12n2/a16v12n2.pdf>. Acesso em: 26 jul. 2016.

MASIEIRO, André Luis. A lobotomia e a leucotomia nos manicômios brasileiros. 2003. Disponível em: <http:// www.scielo.br/scielo.php?script=sci_arttext\&pid=S0104-59702003000200004>. Acesso em: 26 jul. 2016.

MINISTÉRIO PÚBLICO DO ESTADO DO RIO DE JANEIRO. Ministério Público e a tutela à saúde mental. Rio de Janeiro: Sermograf, 2010.

NISE - O coração da loucura. Direção Roberto Berliner. Produção Rodrigo Letier, Luiz Carlos Mello, André Horta e François Wolf. Intérpretes: Glória Pires, Simone Mazzer, Júlio Adrião e Cláudio Jaborandy. Roteiro: Flávia Castro, Mauricio Lissovsky, Maria Camargo, Chris Alcazar, Patricia Andrade, Leonardo Rocha, Roberto Berliner e Bernardo Horta. Brasil: Tv Zero, 2015. (109 min.), son., color.

PAIXÃO, Cristiano. Caso Ximenes Lopes versus Brasil. Corte Interamericana de Direitos Humanos. Relato e Reconstrução Jurisprudencial. 2007. Disponível em: <http://direitosp.fgv.br/sites/direitosp.fgv.br/files/narrativa_final___ximenes.pdf>. Acesso em: 13 set. 2016.

PEREIRA, Caio Mário da Silva. Instituições de Direito Civil. 30. ed. Rio de Janeiro: Forense, 2017.

PIOVESAN, Flávia. Direitos humanos e a jurisdição constitucional internacional. In: GOMES, Eduardo Biacchi; REIS, Tarcísio Hrdaman. O direito constitucional internacional, após a emenda 45/04 e os direitos fundamentais. São Paulo: Lex Editora, 2007. p. 35-60.

RIO GRANDE DO NORTE. Lei no 6.578 de 4 de janeiro de 1995. Disponível em: <http://www.al.rn.gov.br/portal/_ups/legislacao//6.758.pdf>. Acesso em: 28 jul. 2016.

SANTORO FILHO, Antonio Carlos. Direito e saúde mental. 1. ed. São Paulo: Verlu Editora, 2012.

SILVA, Eduardo Jannone da. Tutela jurídica do direito à saúde da pessoa portadora de deficiência. Curitiba: Juruá, 2009.

TARTUCE, Flávio. Direito Civil: lei de introdução e parte geral, volume I. 14. ed. Rio de Janeiro: Forense, 2018. VENOSA, Sílvio de Salvo. Direito civil: parte geral. 17. ed. São Paulo: Atlas, 2017. 